\title{
Um breve atlas do romance português do século XVIII
}

\section{A brief atlas of the Portuguese eighteenth-century novel}

\section{MoIzeIS Sobreira SOUSA*}

Resumo: O romance português do século XVIII tem sido peremptoriamente ignorado ou apontado como quase inexiste pela historiografia literária. Todavia, um exame mais detido da produção romancística dessa época comprova não apenas o cultivo de romance no Portugal Setecentista, mas também a possibilidade de diálogo com romancistas lusitanos do século XIX, afastando a hipótese segundo a qual essa forma surge na faixa oeste da Península Ibérica como mera extensão dos desdobramentos do romance franco-inglês.

Palavras-chave: Romance, século XVIII, século XIX.

Abstract: The Portuguese eighteenth-century novel has been flatly ignored or regarded as almost nonexistent by the literary historiography. However, closer examination of novel production of the period proves not only the cultivation of novel in eighteenth-century Portugal, but also the possibility of dialogue with Lusitanian novelists of the nineteenthcentury, ruling out the hypothesis that this form arises in the western portion of the Iberian Peninsula as a mere extension of the developments of the French-English novel. Keywors: Novel, eighteenth century, nineteenth century.

\footnotetext{
* Pós-Doutorando em História e Teoria Literária pela Universidade de Campinas (UNICAMP). Doutor em Letras | Estudos Comparados de Literaturas de Língua Portuguesa, pela Universidade de São Paulo, com período sanduíche na Universidade de Lisboa. Mestre em Letras pelo Departamento de Letras Clássicas e Vernáculas da Universidade de São Paulo.
} 
o fazer o seu diagnóstico do "estado atual da literatura portuguesa" em 1865, Teófilo Braga é categórico ao afirmar que, naquela época, "lia-se apenas $O$ Feliz Independente" (Braga, 1865: 13), fenômeno que ele atribui à incipiência do cenário literário nacional: desanimado e ainda por se formar. Embora pouco isenta, essa análise ela ajuda a mapear a imagem que os críticos e historiadores da literatura faziam do romance português setecentista durante século XIX, extensiva, vale lembrar, à atualidade. Na advertência que escreveu para a segunda edição de Lendas e Narrativas em 1858, Alexandre Herculano faz um balanço mais otimista, porém não menos reducionista, dos romances que seriam os mais lidos na primeira metade do século XIX. No seu entendimento, Alívio de Tristes (1648), de Mateus Ribeiro, e Feliz Independente (1779) seriam "tiranos que reinavam sem êmulos e sem conspirações na província do romance português" (Herculano, 1980: 8).

Essas obras, que foram escritas nos séculos XVII e XVIII, período supostamente marcado pela ausência de romance em Portugal ${ }^{2}$, não são casos isolados. Embora as histórias literárias não consigam ir além do romance do Padre Teodoro de Almeida e o tomem, a par de outras duas ou três referências (quando muito), como exceção ao hiato ficcional que teria vigorado entre o século XVI e o começo do século XIX, a produção romancística lusitana compreendida nesse lapso se expandiu para além dos limites estabelecidos pelo sistema literário canônico.

Ao se debruçar sobre os pedidos de licença para a circulação de livros submetidos à Censura de Lisboa entre 1795 e 1807, ano em que o século XVIII efetivamente se encerra no mundo luso, Márcia Abreu (2012) colhe dados que auxiliam a redesenhar o mapa da produção e circulação do romance português setecentista. Com base nas informações reunidas por essa pesquisadora, conclui-se que as obras de ficção procedentes de Portugal/Espanha são maioria entre os dez títulos mais requisitados, respondendo por $50 \%^{3}$ do volume licenciado, ao passo que a França é responsável por apenas 30\%, a Itália e Suíça 10\% cada uma e a Inglaterra, que é "tida como central no desenvolvimento do romance moderno"

2 Conferir capítulo III de SOUSA, Moizeis Sobreira de. As fontes setecentistas do romance português. 278 p. Tese (Doutorado) - Faculdade de Filosofia, Letras e Ciências Humanas, Universidade de São Paulo. São Paulo, 2014.

3 Esse percentual engloba as produções do século XVII e XVIII. Se for levado em conta somente o que era escrito nos Setecentos, a porcentagem cai para $40 \%$ do total. Mesmo assim, as produções portuguesas persistem na dianteira do ranking. 
(Abreu, 2012: 8), nem sequer aparece nesse ranking. ${ }^{4}$

\begin{tabular}{|l|c|c|}
\hline \multicolumn{1}{|c|}{ Romance/Autor } & Publicação & Origem \\
\hline Aventuras de Telêmaco, Fénelon & 1699 & França \\
\hline História de Gil Blas, Alain-René de Lesage & 1715 & França \\
\hline Carolina de Litchfield, Isabelle de Montolieu & 1786 & Suíça \\
\hline Dom Quixote, Miguel de Cervantes & $1605-1615$ & Espanha \\
\hline História do Imperador Carlos Magno (Anônimo) & 1490 & França \\
\hline Lances da Ventura, Félix Monroy y Ros & $1793-1797$ & Portugal \\
\hline Viagens de Altina, Caetano de Campos & $1790-1793$ & Portugal \\
\hline Viagens de Henrique Wanton, Zaccaria Seriman & 1749 & Itália \\
\hline O Feliz independente, Teodoro de Almeida & 1779 & Portugal \\
\hline Aventuras de Diófanes, Tereza Margarida Orta & $1752-1777$ & Portugal \\
\hline
\end{tabular}

Lista dos romances que mais solicitaram autorização à Censura de Lisboa para circular entre 1795 e 1807.

É importante salientar que esses dados apresentam algumas limitações. Eles se referem especificamente ao envio de livros de Lisboa para o Rio de Janeiro. Por si só, também não autorizam a tomá-los como único critério para definir os best-sellers desse período. Outras informações, como catálogos de bibliotecas particulares, registro de gabinetes de leitura e a quantidade de edições de cada romance seriam necessários numa contabilização dessa natureza. Além disso, não nos permitem visualizar a outra ponta do circuito, a saber: aquela que dá conta das obras que tiveram o pedido de publicação negado, não só na colônia, mas também na metrópole. Muitas dessas produções, como se sabe, ainda permanecem soterradas pela história literária ou foram sumariamente soterradas pela Censura. A análise desse material, possibilidade que não está ao nosso alcance por agora, permitiria reconstituir, de forma mais completa, o painel sobre o romance português setecentista que ora propomos.

A despeito dessas restrições, os referidos dados são suficientes para comprovar a escritura de romance no Portugal do século XVIII e em dimensões que

4 Optamos por incluir a Espanha ao lado de Portugal porque Dom Quixote, o romance espanhol que figura nessa lista, foi escrito no período em que esses dois países faziam parte do mesmo espaço geopolítico, compartilhando um campo cultural bilíngue. A obra-prima de Cervantes, nesse sentido, é parte indissociável da história do romance português. 
ultrapassam a mera exceção, contrariando o vácuo romancístico que a crítica identifica nessa época. Proporcionalmente, a maior parte dos títulos é assinada por autores portugueses e se concentra exatamente na centúria setecentista. Afora o Feliz Independente, a produção nacional ainda conta com Lances da Ventura, Viagens de Altina e Aventuras de Diófanes, obras cuja importância é acrescida pelo fato de estarem entre as que mais despertavam o interesse dos leitores (não só portugueses, como também brasileiros) no final do século XVIII e início do XIX, o que Ihes assegura, em alguma medida, lugar na constituição do romance como gênero autônomo, tal como ele irrompe e se particulariza nos termos do sistema cultural lusitano.

Em oposição ao que a historiografia literária tem sedimentado como verdade, o peso da França e Inglaterra ${ }^{5}$ não é absoluto, pelo menos no que concerne à escrita e circulação desse gênero no recorte temporal recoberto pela tabela. Em contrapartida, a consideração da produção acanônica, conjunto de que esses romances portugueses fazem parte, é fulcral, pois abre caminho para a detecção das notas dominantes subjacentes à escrita romancística do período em questão, facultando o mapeamento dos gostos e tendências relativas às contingências da interface leitura/escrita. Por fim, é digno de nota ainda o fato dos romances em questão integrarem uma rede de obras certificada pela censura, ocorrência que deixa transparecer, mais uma vez, que as retaliações dessa instituição não impediam o romance, consoante sua elasticidade formal, de cavar túneis nos terrenos literários mais inóspitos à propensão para hospedar conteúdos adversos. ${ }^{6}$

O silenciamento que incide sobre essas obras parece, portanto, ser fruto das escolhas feitas pela historiografia literária, que, por razões ainda desconhecidas, preferiu ignorar a existência desses romances e sustentar a ausência desse gênero no Portugal setecentista. No caso de Lances da Ventura, é possível que o olvido esteja ligado à origem castelhana do autor, motivo que poderá ter levado os historiadores da literatura, ciosos por construir suas narrativas como afirma-

\footnotetext{
5 Os títulos franceses ultrapassam os nacionais apenas do meio para o final da primeira metade do século XIX, momento em que se registra produções inglesas entre as mais lidas.

6 Sobre a relação entre romance e censura conferir capítulo II de SOUSA, Moizeis Sobreira de. As fontes setecentistas do romance português. 278 p. Tese (Doutorado) - Faculdade de Filosofia, Letras e Ciências Humanas, Universidade de São Paulo. São Paulo, 2014.
} 
ção da nacionalidade 7 , a sonegar espaço na história do romance português a Felix Moreno de Monroy y Ros. Nos fundos da Biblioteca Nacional de Lisboa, não constam exemplares dessa obra. ${ }^{8}$ A Torre do Tombo, a seu turno, conserva apenas o tomo $V$ desse texto. Innocencio da Silva foi quem mais reuniu informações sobre esse autor, todavia muito escassas. Em Diccionario bibliographico portuguez, Silva menciona que Monroy y Ros é "hespanhol de nação, mas domiciliario por muitos anos em Lisboa, onde [...] faleceu já no presente seculo" (Silva, 1858: 267), autor do referido romance e de mais duas traduções: Methodo pratico para falar com Deus, traduzido do hespanhol (1779) e Pamella Andrews, ou a virtude recompensada. Novella de Richardson, traduzida em vulgar (1799). Em contrapartida, as edições de Lances da ventura perduraram até a primeira metade do século XIX. No ano de 1843, elas ainda aparecem, conforme Márcia Abreu (2012), como um dos romances mais longamente anunciados nos jornais cariocas. Essa repercussão induz a pensar que Monroy e Ros era um autor relativamente conhecido pelo público leitor e mercado editorial dos séculos XVIII e XIX, o que torna injustificável o seu apagamento no cenário romancístico português.

Mover-se pela lógica da afirmação da nacionalidade levou, em alguma medida, a historiografia literária portuguesa a deixar escapar uma porção considerável de textos produzidos por autores nascidos em Portugal e escritos em casteIhano ou vice-versa. Essa atitude se choca com a permanência do bilinguismo luso-espanhol enquanto prática que marca a vida cultural portuguesa até meados dos séculos XVIII. Desde o século XV, "estabelecera-se entre os dois países uma espécie de simbiose cultural e as alianças matrimoniais entre as famílias reinantes da Espanha e Portugal contribuíram para [acentuar esse fenômeno]" (Teyssier, 2007: 87), cuja prevalência começa a perder força após a Restauração de 1640, evento que terá induzido o soterramento das manifestações culturais bilíngues. No computo dessa lacuna, encontram-se as narrativas picarescas que foram compostas por autores lusitanos e escritas em castelhano e/ou português nos séculos XVII e XVIII.

\footnotetext{
Sobre a relação entre historiografia literária e afirmação da nacionalidade, vide ANASTÁCIO, Vanda. Da História Literária e alguns dos seus problemas. In Brotéria. Lisboa, v. 157, Jul. 2003, p. 45-58.

8 No catálogo da PORBASE (Base Nacional de Dados Bibliográficos), articulado à base da Biblioteca Nacional, o leitor é direcionado para a Biblioteca Municipal de Elvas, onde há uma edição de Lances da ventura.
} 
A terceira parte de Gusmán de Alfarache, ${ }^{9}$ de autoria de um português, Félix Machado da Silva Castro e Vasconcelos (Marques de Montebelo), seguiu em manuscrito até 1927, quando um estrangeiro, Gerhard Moldenhauer, exumou o códice 46-VIII-46 da Biblioteca da Ajuda e o publicou, em Nova-York, no número 155 da Revue Hispanique. Muito provavelmente, as causas desse esquecimento, ainda hoje persistente, não têm ligação com a inabilidade dos historiadores para frequentar arquivos, antes podem estar associadas ao fato do Marques de Montebelo ter construído uma narrativa em castelhano, abertamente oriunda de um texto/gênero de feições tipicamente espanholas. Além disso, deve ter concorrido para tal, a fidelidade que Montebelo manteve à coroa espanhola após os eventos de 1640, o que o colocou na posição de inimigo da nacionalidade, tornando-se consequentemente indigno de figurar na história do romance português, ainda que o gênero cultivado por ele esteja entre as referências estruturantes da escrita romancística em Portugal.

Afora a terceira parte de Gusmán de Alfarache, os pícaros lusitanos notabilizam a Vida de S. Gregório Gadanha (1644), obra que Antônio Henrique Gomes, judeu português e expatriado, publicou na França, e Historia de las cuevas de Salamanca (1737), escrita em castelhano pelo português Francisco Botelho de Morais e Vasconcelos. Em Novelistas e contistas portugueses dos séculos XVII e XVIII, João Palma Ferreira aventa a possiblidade de serem descobertas novas produções portuguesas desse gênero, "abrindo novas pistas para uma investigação apaixonante e provável inventariação das espécies até agora desconhecidas" (cf. Ferreira, 1981: 41), oportunidade que ficará apenas sinalizada aqui.

Dando prosseguimento ao atlas dos romancistas portugueses do século XVIII, importa contornar os silêncios da crítica e incluir nesse rol o Serão político (1704), de Frei Lucas de Santa Catarina, Compêndio narrativo do Peregrino da América (1728), de Nuno Marques Pereira, Brados do desengano (1736), de Sóror Madalena da Glória, A preciosa (1731), de Sóror Maria do Céu, Obras do diabinho da mão furada, Novela despropositada, Novela do zeloso desterrado e Novela Familiar Instrutiva. Em comum, esse conjunto de obras, bem como os demais romances setecentistas aludidos anteriormente, está imerso nalgum tipo de marginalização, seja o esquecimento da crítica, a publicação tardia ou ineditismo, a

9 Originalmente, Gusmán de Alfarache foi escrita por Mateo Alemán, sendo a primeira parte publicada em Madrid, no ano 1599 e a segunda em 1604, na cidade de Lisboa. 
circulação em manuscrito, o uso de pseudônimo e/ou autoria incerta.

A Novela Despropositada, de Frei Simão António de Santa Catarina, ficou em manuscrito por aproximadamente duzentos anos. A sua primeira edição foi levada a cabo somente em 1977, por iniciativa de Nuno Júdice, que resgatou o texto nos arquivos da Biblioteca da Ajuda. As Obras do diabinho da mãe fura$d a$, romance cuja autoria é atribuída, incertamente, a Antônio José da Silva ( 0 Judeu), foram publicadas pela primeira vez um século depois de escrita, entre 1860-1861, pelo diplomata brasileiro Manuel de Araújo Porto Alegre, que tomou como base o manuscrito depositado no acervo da Biblioteca Nacional de Lisboa. Um ano depois, a revista portuguesa Archivo Pittoresco exumou as Obras com o título $O$ fradinho da mão furada: novella diabólica. A Novela do Zeloso Desterrado (1719), manuscrito de autoria ainda desconhecida que encontrei na Biblioteca Nacional, e Novela Familiar Instrutiva ${ }^{10}$ (sem data), de José Joaquim Carneiro de Miranda e Costa, achada no acervo da Biblioteca da Ajuda, ainda não foram trazidas à estampa até o momento.

Segundo informações colhidas por Ferreira (1981), o manuscrito da Novela do Zeloso Desterrado foi adquirido em Londres, num lote que incluía alguns volumes não impressos das Memórias da viagem de Francisco Xavier de Oliveira e de obras referentes aos anos de 1728 a 1737. Essa circunstância aponta para a possiblidade da Novela ter sido escrita pelo Cavaleiro de Oliveira ou alguém próximo a ele. Na capa do códice (catalogado com o número 11041), é dito que ela foi "composta pelo bom ingénio de J. M. e dedicada aos colegiais senhores colegiais de Amesterdão", um grupo que, a julgar pela descrição feita na dedicatória, seria formado por judeus desterrados de Portugal, dentre os quais o autor se incluiria. Seja como for, quem escreveu esse romance tinha a intenção de se salvaguardar no anonimato. Na advertência ao leitor, tecida de um jeito invulgar para a época, o autor, pondo-se como senhor da sua pena, desafia o público e a Censura a dizer tudo que quisessem acerca sua da obra, pois, mesmo que cortassem o texto, antepondo-Ihe restrições ou críticas severas, não seriam capazes de penalizá-lo, de maneira a arrancar-lhe "couro e cabelo", já que não saberiam o seu nome.

O diálogo com a audiência, característica tão comum a romancistas do século $\mathrm{XIX}$, tais como Camilo Castelo Branco, propicia acompanhar o percurso que o

10 O título Novela Familiar Instrutiva é seguido pelo subtítulo com explicação de todas as virtudes morais que contribuem para a boa educação, conduta e felicidade das famílias. 
autor da Novela do Zeloso Desterrado supõe para o seu texto. Ao se reportar aos colegiais de Amsterdã e aos leitores em geral, ele vislumbra a possibilidade de circulação nesses circuitos, o que aconteceu em alguma medida. A análise do manuscrito que se encontra na Biblioteca Nacional de Lisboa leva a crer que o romance passou por muitas mãos. Após deixar o autor, o texto foi reproduzido algumas vezes e por mais de uma pessoa. A cópia encontrada em Londres, que já havia sido transcrita a partir do original, continha duas caligrafias diferentes. Em 1981, um funcionário da BN, L. de Carvalho Dias, fez outra reprodução do texto. Entre esse intervalo, a probabilidade de outras transcrições terem sido faturadas é muito grande.

A Novela Familiar, por sua vez, catalogada com a inscrição 50-I-57, conta com 400 folhas e foi escrita durante o reinado de D. Maria I, a quem o romance é dedicado nestes termos: "Dedicada à Real Proteção de S.M.F. Augustíssima Rainha Nossa Senhora". Malgrado a impossibilidade de definir com precisão o ano em que ela foi composta, pode-se afirmar que a sua datação remonta ao final do século XVIII. Na primeira página do códice, o autor se apresenta como juiz de fora da Vila da Campanha da Princesa (atual cidade de Campanha, Minas Gerais) ${ }^{11}$, cargo que ele passa a exercer em 1798, quando D. Maria I determina a elevação dessa localidade à categoria de vila.

Como esses últimos dois romances, é possível resgatar muitos outros exemplares que ainda permanecem sob a poeira das seções de manuscritos e obras raras/antigas da Biblioteca Nacional (Lisboa e Rio de Janeiro), ${ }^{12}$ Biblioteca da Ajuda, Torre do Tombo, Biblioteca do Palácio de Mafra, Biblioteca das Universidades de Coimbra e Évora, nos arquivos da Academia das Ciências de Lisboa ou ainda nos registro da Censura, onde se encontra a relação das obras nacionais que tiveram a licença de publicação negada.

11 Apesar de atuar como funcionário da Coroa no Brasil, José Joaquim Carneiro de Miranda e Costa era português. No Registro Geral de Mercês de D. Maria I, no livro 20, f. 265, conforme registro da Torre do Tombo, consta que Miranda e Costa exercia o cargo de juiz de fora da Vila de Alandroal em 1786, o que nos autoriza a incluir a Novela Familiar Instrutiva no rol dos romances portugueses.

12 A transferência, para o Brasil, de parte significa do acervo da Biblioteca da Ajuda e de outras bibliotecas ligadas à Coroa em 1807, nos leva a pensar que alguns exemplares da produção romancística dos Setecentos podem ter acompanhado a Família Real, sendo, mais tarde, anexados ao catálogo da Biblioteca Nacional do Rio de Janeiro, instituição cuja formação está diretamente ligada à referida transferência. 
De modo geral, a exígua atenção dispensada aos romances portugueses do século XVIII, além dos preconceitos e reducionismos aludidos anteriormente, costuma associá-los peremptoriamente à novela alegórica, às convenções neoclássicas, ao misticismo católico tridentino, ao artificialismo e exagero da representação barroca ou ao tom didático e sentimental, lugares-comuns que são invocados para circunscrever essa produção nos termos de uma literatura que se dilui na penumbra da irrealidade, distante, com efeito, das matrizes realistas que singularizam o romance como forma autônoma. Em que pese a incidência desses invólucros barrocos e/ou classicizantes, a ficção setecentista compõe um quadro mais denso e complexo, radicado na interpenetração de modelos composicionais divergentes e na relação ambígua com as instituições político-culturais. Assim, atitudes didáticas e alegóricas, aparentemente comprometidas com o discurso oficial, compartilham o espaço romancístico com intersecções timbradas de realismo e/ou lances picarescos.

Seguindo essa orientação sinuosa, A Novela do Zeloso Desterrado pactua com a representação da catequese católica, assumindo, por exemplo, que "toda fermosura mundana [...] não pode ser permanente", sem deixar, no entanto, de acolher as "letras humanas" e um conteúdo judaizante sub-reptício. De igual modo, a Novela Despropositada se vale de um tecido narrativo múltiplo, no qual assimila parodicamente o tom patético-sentimental das cantigas de temática amorosa ou entrelaça as constantes referências que faz ao universo fisiológico-sexual a uma ornamentação frásica sobrecarregada de expedientes barrocos e clássicos. Esse arranjo pode ser ilustrado na passagem em que o protagonista, José Patrício Pereira dirige um soneto a Maricas, dama por quem ele se apaixona:

"Ay dolor! Ay dezeo! Ay cuidado! / que quereis a um visconde enamorado?" dizia o Moço alinhando o seu desalinhado corpo. E, determinado dar um passeio pela porta da sua Querida, posto a caminho viu-se à janela e escarrou-Ihe este Soneto que tinha achado não sei onde:

\section{SONETO}

Que galante que estás, linda, e bizarra!

Os teus dentes parecem de uma serra! 
Quando Vénus te vir, logo te encerra;

e o meu amor então logo escarra.

Ora mostra-me já essa mascarra

pois sabes que minha alma por ti berra:

Dá-me tantos cabelos como terra

para trazer por prenda na samarra.

Não tenhas, não, Senhora, tanta birra;

porque a birra às Formosas tudo borra.

Eu não sei na verdade quem me empurra.

Olha que esta alma só por ti se mirra;

e na grimpa, por dó, traz uma gorra,

ó Barra, Berra, Birra, Borra, Burra! (Santa Catarina, 1977: 27)

Em primeiro lugar, convém notar a incidência de um invólucro poético-amoroso que vai sendo preenchido com uma linguagem grosseira, quase infamante, o que finda por subverter a função habitual do soneto, que, como se sabe, converge para o tratamento de assuntos sérios e elevados. Assim, a declamação dos versos é equiparada ao ato fisiológico de escarrar ou ao gesto animalesco de berrar. A configuração da mulher amada, embora invocada através do termo linda e Senhora, possível reminiscência das cantigas de amor, também se reveste de imagens grotescas, como a semelhança bizarra apontada entre seus dentes e uma serra, transbordando, desse modo, os limites da alocução encomiástica. Para compor esse quadro, signatário de uma arquitetura textual multidimensional, o narrador lança mão de uma série de hibridismos: a poesia imbricada na prosa, o sublime intercalado ao rebaixado, a cantiga, modelo popular, misturada ao soneto, que é uma forma erudita, e ao jogo barroco da afirmação e negação. Por fim, o uso do português é acrescido do espanhol, ocorrência que se manifesta por mais de uma vez ao longo do romance, assinalando, conforme sugerido antes, para a incidência do bilinguismo como marca que persiste na produção romancística portuguesa do século XVIII.

Outro exemplo emblemático da densidade estrutural implicada na ficção setecentista é Obras do diabinho da mão furada. Embora o protagonista, André 
Peralta, se apresente como um católico convicto, chegando, no desfecho da narrativa, a vestir o "hábito do seráfico Padre São Francisco" (Silva, 2006: 182) no convento de Xabregas, ele atravessa a narrativa na companhia de um diabo, o ambíguo e ardiloso Fradinho/Diabinho da mão furada, com quem perambula no caminho de Évora até Lisboa, praticando travessuras e aplicando embustes característicos de anti-heróis e malandros, o que permite traçar um itinerário descendente que desemboca no romance picaresco, onde estão seus irmãos Lazarillo de Tormes, Guzmán de Alfareche e os primos cervantinos das Novelas Exemplares.

Jerusa Pires Ferreira defende que as Obras se revestem "de todas as malícias da picaresca, num desafio à Inquisição e seus processos" (Pires, 1995: 31), acondicionamento operado a partir de um acentuado malabarismo textual, capaz de construir um protagonista que é apresentado como "limpo de sangue, não é sovina e come carne de porco" (Pereira, 2006: 30), o que certifica a sua boa procedência cristã. Todavia, nas interlocuções que estabelece com o diabo, os membros do clero, excetuando-se alguns bons, surgem retratados como "grandes indagadores das vidas alheias, desleais, ambiciosos, amancebados, movidos pela ausência de pasto espiritual, sendo, em suma, a pior gente que há no Mundo" (cf. Silva, 2006: 96). Assim, conforme nota Kênia Pereira (2006), as várias vezes em que Peralta insiste em se passar por temente a Deus e à Santa Igreja, "devem sempre ser encaradas como jogo de linguagem. Sob a pele desse discurso católico, esconde-se a fala de um cristão-novo ou cripto-judeu disposto a denunciar os tomentos vividos na mão da Inquisição e, ao mesmo tempo, driblar a censura" (Pereira, 2006: 31). Esse jogo furta-cor se reflete também na constituição do Diabinho, que aparece em cena sob o disfarce do Fradinho, o que leva Kênia Pereira (2006) a se perguntar se não estaria Antônio José da Silva, através do emprego de uma simbologia popular (diabo em forma de frade), vingando-se sutilmente do Santo Ofício e de seus inoportunos algozes.

Em A dialética da camuflagem nas Obras do diabinho da mão furada, Maria Thereza Abelha Alves, chama atenção, nesse sentido, para a inversão das categorias do divino e do diabólico, que, tal como num jogo carnavalesco, confere às personagens elasticidade para irem-se transformando ao longo da narrativa-brincadeira. A hipótese da carnavalização também é referendada por Kênia Pereira, para quem o romance de Antônio José da Silva é embebido da cultura popular carnavalizada, que, pelo riso, vence o tom sério e oficial das instituições 
portuguesa do século XVIII, burladas sob os auspícios de uma ação que instaura a zombaria, o achincalhe e a desmistificação.

Para galgar esse grau de elaboração, o Judeu recorre a uma forma de representar que entrecruza diferentes camadas de realidade. Historicamente circunstancializada, a ação se passa no final do século XVI, no tempo de Felipe II, de quem André Peralta fora soldado na região de Flandres. A esse pano de fundo, o narrador acrescenta o onírico e visões para apresentar o quadro social que desenrola. Na segunda parte da narrativa, Peralta é levado, em sonho, pelo diabo ao inferno, cenário onde são desveladas as engrenagens que movem a sociedade portuguesa. Malgrado a contextura insólita que circunda esse espaço, as personalidades que desfilam por ele carregam as idiossincrasias, vícios e paixões inerentes ao mundo setecentista. Nessa tela, se movimenta, sob o olhar zombeteiro do diabo e a visão pretensamente cândida do soldado, a corrupção e arrogância dos nobres, a venalidade dos funcionários da Coroa, a luxúria dos freiráticos, o zelo farisaico do clero e até mesmo o rei, cuidadosamente cingido na figura de Saul.

Na sequência desse episódio, o diabo mostra a visão do palácio dos sete pecados capitais a André Peralta. Proeminentemente alegórica, essa cena se propõe a mergulhar nas entranhas da condição humana, descolando-se, para tanto, de uma circunscrição geográfica específica. $O$ demônio insiste que aquilo que vai passando diante dos olhos do protagonista é uma representação, o que assegura uma interligação com a realidade tangível, cuja captação exige, num contexto de vigilância, um fazer artístico autodefensivo, em que os acordes oblíquos e metafóricos da consciência narrativa são apresentados como um meio ágil para se contornar os mecanismos de controle literário e intelectual.

Um exame mais apurado das Obras do diabinho da mão furara e de diversos outros romances portugueses do século XVIII permite comprovar não apenas o cultivo desse gênero, mas também a possibilidade de diálogo entre romancistas lusitanos dos séculos XVIII e XIX. Essa possiblidade, também ignorada pelos estudos literários, adquire importância enquanto elemento que ajuda a entender a maneira como o romance português oitocentista se estrutura, levando em conta, desse modo, a herança que ele incorpora da tradição ficcional setecentista local, hipótese que coloca em causa a tese segundo a qual a ascensão dessa forma no século XIX em Portugal teria se dado exclusivamente pela via da importação 
do formato romancístico franco-inglês. ${ }^{13}$

A irradiação do patrimônio ficcional lusitano setecentista é perceptível nas obras de figuras cardeais do romance português dos Oitocentos, como Alexandre Herculano, José Joaquim Rodrigues de Bastos (Conselheiro Bastos) e Camilo Castelo Branco. Em Pároco de Aldeia (1825), Herculano faz menção explícita ao Fradinho da mão furada. Ainda que não seja possível afirmar se a referência diz respeito ao romance de Antônio José da Silva ou à lenda homônima, muito recorrente na cultura oral-popular e fonte usada pelo Judeu, fica a certeza de que o autor de Eurico conhece o repositório narrativo em questão e o recupera na construção do seu texto. ${ }^{14}$ Em A Brasileira de Prazins (1882), Camilo se vale do romance $A$ Preciosa, da freira Maria do Céu, como um interlocutor de destaque. Assim, o processo de criação da protagonista Marta de Prazins, perpassada pela aventura ambígua que articula a busca por Deus ao desejo carnal e proibido por José Dias, se filia abertamente ao drama, também ambíguo, da heroína de $A$ Preciosa como parâmetro comparativo.

A Virgem da Polônia, do Conselheiro Bastos, romance que aparece entre os mais lidos em Portugal no intervalo que vai da década de 1840 até 1860 , segundo levantamento de Luís Sobreira (2001), é outro exemplo da utilização do legado ficcional setecentista lusitano pelo romance do século XIX. Essa obra é signatária emblemática do timbre moralizante dos Setecentos, configurando-se "[...] essencialmente como uma continuação das obras do Padre Teodoro de Almeida" (Sobreira, 2001, p. 9). De modo semelhante ao que ocorre em Feliz Independente, a ação do romance em questão, orientada pelo desejo de depurar os pressupostos axiológicos cristãos, transita por um cenário exótico, mas sempre com a preocupação de interligá-lo a um enquadramento histórico-cultural português. Nesse sentido, é imprescindível notar que "o êxito do Conselheiro Bastos traduz a permanência de uma procura importante de literatura edificante" (Sobreira, 2001: 3), demanda que sinaliza para determinadas tonalidades das preferências

13 Conferir capítulo introdutório de SOUSA, Moizeis Sobreira de. As fontes setecentistas do romance português. 278 p. Tese (Doutorado) - Faculdade de Filosofia, Letras e Ciências Humanas, Universidade de São Paulo. São Paulo, 2014.

14 A referência, tal como aparece no Pároco de Aldeia, diz o seguinte: "A alhada da porta da igreja, nascida daquelas tafularias tolas do Manuel da Ventosa e de sua companheira, acabou de divulgar o negócio, sem que nisso andasse o Fradinho da mão furada nem os jesuítas, gente de poder misterioso e terrível, nem, finalmente, o judeu errante, que tantas maravilhas obra atualmente na terra" (Herculano [s.d.] apud Simões, 1987, p. 256). 
de leitura ficcional. Familiarizado ao gosto do público, o autor da Virgem encontra, na força da tradição romancística dos Setecentos, insumos para a construção da sua obra. Em última análise, está-se diante de uma situação que evidencia a intimidade do público-escritor-mercado editorial oitocentista com um modelo literário fortemente enraizado na tradição romancística setecentista local.

Dentro do que foi possível apresentar no âmbito de um artigo, cabe reiterar, à guisa de conclusão, que as teses que defendem a (quase) inexistência do romance português no século XVIII são insustentáveis diante do volume romancístico produzido nessa época. Volume que pode ser ainda maior, se for considerando que muitas dessas produções continuam soterradas e/ou silenciadas pela historiografia literária. É possível que essa atitude esteja ligada ao equívoco de totalizar o romance de tradição franco-inglesa dos séculos XVIII e XIX como uma forma acabada e pioneira. Assim, considera-se que o surgimento do romance português decorre da importação desse modelo durante os Oitocentos. Assim, as manifestações romancísticas locais e anteriores à ascensão do referido modelo são reputadas por inexistentes ou de pouco valor. Entretanto, se consideradas, elas podem elucidar melhor os caminhos que o romance português assume, sobretudo no século XIX, quando galga a condição de centro da vida literária nacional. 


\section{Referências}

ABREU, Márcia. A circulação de romances como problema para a história literária. Campinas: Escola São Paulo de Estudos Avançados sobre a Globalização da Cultura no Século XIX, 2012.

ANASTÁCIO, Vanda. Da História Literária e alguns dos seus problemas. In Brotéria. Lisboa, v. 157, Jul. 2003, p. 45-58.

ALVES, Maria Thereza Abelha. A dialética da camuflagem na Obras do diabinho da mão furada. Lisboa: Imprensa Nacional-Casa da Moeda, 1983.

BRAGA, Teófilo. As theocracias literárias: relance sobre o estado actual da literatura portugueza. Lisboa: Typographia Universal, 1865.

FERREIRA, Jerusa Pires. Fausto no horizonte. São Paulo: Educ-Hucitec, 1995.

FERREIRA, João Palma. Novelistas e contistas portugueses dos séculos XVII e XVIII. Lisboa: Imprensa Nacional-Casa da Moeda, 1981.

HERCULANO, Alexandre. Lendas e Narrativas. 2 v. Amadora: Livraria Bertrand, 1980.

PEREIRA, Kênia Maria de Almeida. As muitas aventuras de André Peralta e seu companheiro endiabrado ou um soldado pícaro às voltas com o demônio. In SILVA, Antônio José. Obras do diabinho da mão furada. São Paulo: Imprensa Oficial, 2006, p. 15-46.

SANTA CATARINA, Frei Simão António de. Novela Despropositada. Lisboa: Assírio e Alvim, 1977.

SILVA, Antônio José de. Obras do diabinho da mão furada. São Paulo: Imprensa Oficial, 2006.

SILVA, Innocencio Francisco. Diccionario bibliographico portuguez: A-Z. Lisboa: Imprensa Nacional, 1858.

SIMÕES, João Gaspar. Perspectiva Histórica da Ficção Portuguesa: das Origens ao Século XX. Lisboa: Publicações Dom Quixote, 1987.

SOBREIRA, Luis. Uma imagem do campo literário português no período romântico através dos best-sellers produzidos entre 1840 e 1860. In IV Congresso Internacional da Associação Portuguesa de Literatura Comparada, Évora. Atas. Évora: Universidade de Évora, 2001, p. 1-15.

SOUSA, Moizeis Sobreira de. As fontes setecentistas do romance português. 278 p. Tese (Doutorado) - Faculdade de Filosofia, Letras e Ciências Humanas, Universidade de São Paulo. São Paulo, 2014.

TEYSSIER, Paul. Tipos de língua e bilinguismo. In MAGALHÃES, Isabel Alegro de (Org.). História e Antologia da Literatura Portuguesa: Século XVI. v. II. Tomo I. Lisboa: Fundação Calouste Gulbenkian, 2007, p. 87-89. 